\title{
Neurobiological roots of psychopathy
}

This article has been corrected since Advance Online Publication and a correction is also printed in this issue

\author{
Jari Tiihonen $\mathbb{D}^{1,2} \cdot$ Marja Koskuvi $^{1,3} \cdot$ Markku Lähteenvuo $\mathbb{B}^{1} \cdot$ Pekka L. J. Virtanen ${ }^{4} \cdot$ Ilkka Ojansuu ${ }^{1} \cdot$ Olli Vaurio $^{1}$. \\ Yanyan Gao $\mathbb{1}^{3} \cdot$ Ida Hyötyläinen ${ }^{3} \cdot$ Katja A. Puttonen ${ }^{3}$ - Eila Repo-Tiihonen ${ }^{1}$ Tiina Paunio ${ }^{5,6,7,8}$. \\ Marja-Riitta Rautiainen ${ }^{1,5,6} \cdot$ Sasu Tyni ${ }^{9} \cdot$ Jari Koistinaho ${ }^{3,4} \cdot$ Šárka Lehtonen $\mathbb{1}^{3,4}$
}

Received: 21 February 2019 / Revised: 5 April 2019 / Accepted: 13 May 2019 / Published online: 27 August 2019

(c) The Author(s) 2019. This article is published with open access

\begin{abstract}
Psychopathy is an extreme form of antisocial behavior, with about 1\% prevalence in the general population, and 10-30\% among incarcerated criminal offenders. Although the heritability of severe antisocial behavior is up to 50\%, the genetic background is unclear. The underlying molecular mechanisms have remained unknown but several previous studies suggest that abnormal glucose metabolism and opioidergic neurotransmission contribute to violent offending and psychopathy. Here we show using iPSC-derived cortical neurons and astrocytes from six incarcerated extremely antisocial and violent offenders, three nonpsychopathic individuals with substance abuse, and six healthy controls that there are robust alterations in the expression of several genes and immune response-related molecular pathways which were specific for psychopathy. In neurons, psychopathy was associated with marked upregulation of RPL1OP9 and ZNF132, and downregulation of $C D H 5$ and $O P R D 1$. In astrocytes, RPL1OP9 and MT-RNR2 were upregulated. Expression of aforementioned genes explained 30-92\% of the variance of psychopathic symptoms. The gene expression findings were confirmed with qPCR. These genes may be relevant to the lack of empathy and emotional callousness seen in psychopathy, since several studies have linked these genes to autism and social interaction.
\end{abstract}

\section{Introduction}

In developed countries, a relatively small group of antisocial recidivistic offenders commits the majority of all

Supplementary information The online version of this article (https:// doi.org/10.1038/s41380-019-0488-z) contains supplementary material, which is available to authorized users.

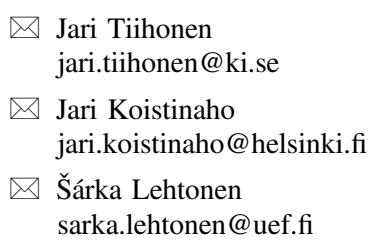

1 Department of Forensic Psychiatry, Niuvanniemi Hospital, University of Eastern Finland, Niuvankuja 65, FI-70240 Kuopio, Finland

2 Karolinska Institutet, Department of Clinical Neuroscience, Centre for Psychiatry Research, Stockholm County Council, Byggnad R5, SE-171 77 Stockholm, Sweden

3 A.I. Virtanen Institute for Molecular Sciences, University of Eastern Finland, PO Box 1627, FI-70211 Kuopio, Finland violent crimes. The prevalence of antisocial personality disorder (ASPD) is $1-3 \%$ in the general population and $40-70 \%$ in prison populations, and the corresponding figures for its most severe manifestation, psychopathy, are about $1 \%$ in the general population and $10-30 \%$ among incarcerated offenders [1-5]. ASPD is characterized by aggression, hostility, callousness, manipulativeness, deceitfulness, and impulsivity, and psychopathy is an

4 Neuroscience Center, Helsinki Institute of Life Science, University of Helsinki, Haartmaninkatu 3, FI-00014 Helsinki, Finland

5 Department of Mental Health and Substance Abuse Services and Public Health Genomics Unit, National Institute for Health and Welfare, PO Box 30, FI-00271 Helsinki, Finland

6 Institute of Clinical Medicine, Department of Psychiatry, University of Helsinki, PO Box 22 (Välskärinkatu 12), FI-00014 Helsinki, Finland

7 Department of Psychiatry, Helsinki University Central Hospital, PO Box 590 (Välskärinkatu 12), FI-00029 Helsinki, Finland

8 Finnish Institute of Occupational Health, Development of Work and Work Organizations, Topeliuksenkatu 41 b, FI- 00290 Helsinki, Finland

9 The Criminal Sanctions Agency, Lintulahdenkatu 5, FI-00530 Helsinki, Finland 
extreme manifestation of ASPD. Severe antisocial and criminal behavior has a substantial genetic component [6]. This far only one study has reported contributing genes reaching genome-wide significance for ASPD [7], although two studies have found association between singlenucleotide polymorphisms and broad spectrum of antisocial behavior [8, 9]. LINC00951, the gene associated with imprisoned offenders with ASPD, codes for long intergenic noncoding RNA, which is expressed especially in the frontal cortex and cerebellum. Its function is not known [7], but it has been linked to autoimmune disease [10]. The gene linked to adult antisocial behavior, $A B C B 1$, is also highly expressed in the brain, and implicated in substance abuse [9]. No underlying molecular pathways of severe antisocial and criminal behavior are known, but there is preliminary evidence on dysregulation of the endogenous opioid system and brain opioid receptors [11-13] in antisocial individuals. Also abnormal glucose metabolism leading to hypoglycemia has been observed as the strongest predictor for violent crimes [14]. A recent study has also found association between immune-related gene sets and antisocial behavior [9]. We aimed to study the neurobiological background of psychopathy by using induced pluripotent stem cell (iPSC)derived cortical neurons and astrocytes, and included also nonpsychopathic substance abusers in addition to healthy individuals as control groups in order to distinguish the putative role of the coexisting substance dependence.

\section{Material and methods}

We generated and fully characterized iPSC lines from six antisocial violent offenders, three nonviolent substance abusers and six control subjects without antisocial traits or substance abuse disorders. Due to the explanatory nature of the study, no power analysis based on predefined effect size was done. The clinical and sociodemographic characteristics of the study subjects are shown in Table 1 . We chose to differentiate the cells into cortical neurons expressing markers of glutamatergic and GABAergic neurons and to astrocytes. Methods for iPSC production and their characterization, derivation of neurons and astrocytes and their analyses are reported in detail in Supplementary Material.

Table 1 Clinical and sociodemographic characteristics of study subjects

\begin{tabular}{|c|c|c|c|c|c|}
\hline & Age & Diagnosis & $\begin{array}{l}\text { Number of } \\
\text { committed homicides }\end{array}$ & $\begin{array}{l}\text { Number of } \\
\text { violent crimes }\end{array}$ & PCL-R score \\
\hline Subject 1 & 30 & $\begin{array}{l}\text { Antisocial personality disorder, ADHD, alcohol dependence, } \\
\text { benzodiazepine abuse, multiple sclerosis, asthma }\end{array}$ & 2 & 19 & 37.0 \\
\hline Subject 2 & 42 & Antisocial personality disorder, alcohol dependence & 3 & 4 & $\begin{array}{l}\text { Not } \\
\text { available }\end{array}$ \\
\hline Subject 3 & 49 & Antisocial personality disorder, alcohol dependence & 2 & 11 & 30.0 \\
\hline Subject 4 & 43 & $\begin{array}{l}\text { Antisocial personality disorder, alcohol dependence, } \\
\text { polysubstance dependence }\end{array}$ & 2 & 7 & 33.7 \\
\hline Subject 5 & 30 & $\begin{array}{l}\text { Antisocial personality disorder, alcohol dependence, opioid } \\
\text { dependence, cannabis dependence, benzodiazepine } \\
\text { dependence, amphetamine dependence }\end{array}$ & 3 & 8 & 36.0 \\
\hline Subject 6 & 47 & $\begin{array}{l}\text { Antisocial personality disorder, borderline personality disorder, } \\
\text { paranoid personality disorder, alcohol dependence, } \\
\text { polysubstance dependence, amphetamine dependence, } \\
\text { hepatitis C }\end{array}$ & 2 & 9 & 37.0 \\
\hline Subject 7 & 38 & Alcohol dependence & 0 & 0 & 2 \\
\hline Subject 8 & 25 & Alcohol dependence & 0 & 0 & 3 \\
\hline Subject 9 & 31 & Alcohol dependence, cannabis dependence, bulimia & 0 & 0 & 11 \\
\hline Subject 10 & 44 & None & 0 & 0 & 3 \\
\hline Subject 11 & 28 & None & 0 & 0 & 2 \\
\hline Subject 12 & 28 & None & 0 & 0 & 1 \\
\hline Subject 13 & 47 & None & 0 & 0 & 3 \\
\hline Subject 14 & 26 & None & 0 & 0 & 2 \\
\hline Subject 15 & 51 & None & 0 & 0 & 1 \\
\hline
\end{tabular}

All individuals were males. Subjects 1-6 are violent offenders, 7-9 are individuals with substance abuse but without criminal behavior, and 10-15 are healthy controls. The biological fathers of Subject 1, Subject 3, and Subject 5 had prison convictions due to violent and nonviolent crimes. None of the biological mothers had been convicted into prison

$P C L-R$ psychopathy checklist revised 


\section{Description of subjects}

Six male offenders were identified by the history of their criminal convictions from the Finnish National Crime Register and recruited through the penal system and classified as extremely violent offenders as described in Tiihonen et al. [5]. Three individuals having substance dependence without violent behavior were recruited from the local substance abuse rehabilitation center, and six healthy controls were recruited from the staff of Niuvanniemi Hospital. The participants were interviewed with Structured Clinical Interview for DSM-IV-Disorders to exclude individuals with a psychosis diagnosis, and to assess whether or not the subject fulfilled criteria for ASPD. Also, any history of substance abuse (alcohol, heroin, buprenorphine, amphetamine, cannabis, other) was obtained through a questionnaire. The history of criminal convictions was obtained from the National Crime Register [5]. Psychopathy ratings with the Hare Psychopathy Checklist revised (PCL-R) [1] were done by accredited rater OV using official crime register data and forensic mental examination reports (violent offenders), and clinical interview (individuals with substance dependence, healthy controls). Informed consent was obtained from all subjects. This study was approved by the Ethics Committee for Pediatrics, Adolescent Medicine and Psychiatry, Hospital District of Helsinki and Uusimaa, and the Criminal Sanctions Agency of Finland.

\section{Generation of hiPSCs and their characterization}

The hiPSC lines were derived from individuals' skin fibroblasts (Supplementary Table 1, Supplementary Figs. 1 and 2). The fibroblasts were isolated and expanded in fibroblast culture media containing Iscove's DMEM media (Thermo Fisher Scientific) with $20 \%$ fetal bovine serum, $1 \%$ Penicillin-Streptomycin and $1 \%$ nonessential amino acids. iPSC reprogramming was performed by the CytoTunE-iPS 2.0 Sendai Reprogramming Kit (Thermo Fisher Scientific) according to the manufacturer's instructions. The iPSCs were grown on Matrigelcoated dishes (BD Biosciences) in E8 medium (Gibco). Medium was changed every other day and hiPSC colonies were enzymatically passaged using $0.5 \mathrm{mM}$ EDTA (Gibco). The pluripotency of hiPSCs was confirmed by expression of pluripotent markers using immunocytochemistry (Oct-4, Sox2, TRA-1-81, and SSEA4) and qPCR (OCT-4, SOX-2, NANOG, and LIN-28). The embryoid body formation assay showed hiPSCs properties to differentiate into all three germ layers. In this assay, hiPSCs were proliferated in low-adherent plates for 2 weeks after which the EBs were plated down on Matrigel-coated plates for an additional two weeks. The expression of smooth muscle actin positive cells (mesoderm), BIIITubulin-positive cells (ectoderm), and alpha-fetoprotein positive cells (endoderm) was confirmed by immunocytochemistry. The clearance of Sendai virus was measured by qPCR, and United Medix Laboratories Ltd in Helsinki (Finland) confirmed normal karyotype of each cell line.

\section{hiPSC differentiation to neural precursor cells (NPCs) and cortical neurons}

Neural differentiation was performed according to Hicks et al. [15] with minor modifications. hiPSC colonies growing on Matrigel-coated plates are exposed to dual SMAD inhibitors $(10 \mu \mathrm{M}$ SB431542 and $200 \mathrm{nM}$ LDN-193189) for 10 days in neural differentiation medium containing a 1:1 mix of DMEM/F12 and Neurobasal medium supplemented with $1 \%$ B27 supplement, $0.5 \%$ $\mathrm{N} 2$ supplement, $2 \mathrm{mM}$ Glutamax, $50 \mathrm{IU} / \mathrm{ml}$ penicillin, and $50 \mu \mathrm{g} / \mathrm{ml}$ streptomycin (all from Gibco). After the induction, $25 \mathrm{ng} / \mathrm{ml}$ bFGF (R\&D Systems) was added for additional 2 days to expand the differentiated neuroepithelial cells in rosettes. Rosettes were detached and plated into ultralow attachment dishes (Corning) in neural sphere medium (NSM), consisting of a 1:1 mix of DMEM/F12 and Neurobasal medium supplemented with $1 \% \mathrm{~N}_{2}$ supplement, $2 \mathrm{mM}$ Glutamax, $50 \mathrm{IU} / \mathrm{ml}$ penicillin, and $50 \mu \mathrm{g} / \mathrm{ml}$ streptomycin (all from Gibco) supplemented with $25 \mathrm{ng} / \mathrm{ml}$ bFGF. During the differentiation, half of the medium was renewed every other day and the spheres were manually cut once a week to maintain NPC population. For experimental purposes, NPCs were dissociated with Accutase and plated in NSM media onto PORN/Matrigel-coated plates (with density $2-3 \times 10^{6}$ cells $/ 6 \mathrm{~cm}$ dish; $1 \times 10^{6}$ cells $/ 6$-well plate or 100,000 cell/24-well plate). The neurons were matured for 1 week before experiments. Immunocytochemistry results showing the fractions of glutamatergic and GABAergic cells are presented in Supplementary Fig. 3.

\section{hiPSC differentiation to astrocytes}

We have adapted a previously published protocol for the differentiation of hiPSC-derived astrocytes [16]. Briefly, due to the same origin of neurons and astrocytes, hiPSCs were differentiated into neuroepithelial cells by using the same procedure as for neuron differentiation for the first 10 days. The neural progenitors were detached to ultralow attachment dishes and expanded in astrocyte sphere medium, i.e., DMEM/F12 medium supplemented with $1 \% \mathrm{~N}_{2}$ supplement, $2 \mathrm{mM}$ Glutamax, $50 \mathrm{IU} / \mathrm{ml}$ penicillin, and 50 $\mu \mathrm{g} / \mathrm{ml}$ streptomycin (all from Gibco), $5000 \mathrm{KY} / \mathrm{ml}$ Heparin (LEO), $10 \mathrm{ng} / \mathrm{ml} \mathrm{bFGF}$ and $10 \mathrm{ng} / \mathrm{ml}$ EGF (both from R\&D Systems). Half of the medium was renewed every other day 
and the spheres were manually cut once a week. According to our experience, this method generates a homogenous population of astrocyte progenitor cells within 4 months of differentiation. The astrocytes were further maturated on Matrigel-coated plates by treatment with $10 \mathrm{ng} / \mathrm{ml} \mathrm{CNTF}$ and $10 \mathrm{ng} / \mathrm{ml} \mathrm{BMP4}$ (both from PeproTech) for 1 week in a density of 600,000 cells/6-well plate or 80,000 cell/24well plate.

Methods concerning immunocytochemistry, RNA isolation, gene expression profile, qRT-PCR, and quantitative proteomic analysis are described in detail in Supplementary Material.

\section{Results}

Supplementary Tables 2 and 3 show all differentially expressed genes in neurons and astrocytes, respectively, up to nominal significance $(p<0.05)$ between violent offenders and control subjects. Since cultivation of neurons failed from cells of one healthy control, there were 14 individuals in the analyses concerning neurons, and 15 individuals in the analyses concerning astrocytes. Differentially expressed genes surviving correction for multiple comparisons in cortical neurons are shown in Table 2. Of these genes, in neurons, ribosomal RPL1OP9 pseudogene showed over tenfold upregulation in violent offenders as compared with healthy controls and nonviolent individuals with substance abuse. Also zinc finger protein 132 (ZNF132) gene was markedly upregulated, and cadherin 5 (CDH5) gene markedly downregulated among the neurons derived from cells of violent offenders. Figure 1 displays the qPCR replications of these results (except for RPL10P9 due to no suitable primers being available), and correlations between gene expression levels and psychopathy score (PCL-R). Pearson's correlations between gene expression and PCL-R score were $0.67(p=0.013, N=13$; see Fig. 2) for $R P L 10 P 9,0.96(p=0.000, N=13)$ for $Z N F 132,-0.65$ $(p=0.015, N=13)$ for $C D H 5$, and $-0.55(p=0.05, N=$ 13) for opioid receptor delta 1(OPRD1). $C D H 13$ gene encoding a cadherin that regulates axon growth during neural differentiation, has been previously linked to extremely violent behavior [5], but it did not achieve statistically significance $(p=0.24)$ in this study, possibly because it is most prominently expressed by oligodendrocytes in the brain. Although the result for RPL1OP9 could not be verified with qPCR due to missing suitable primers, the same result for significant correlation with PCL-R score and upregulation of the gene in the gene array was also discovered in the astrocytes differentiated from the hiPSCs lines [Pearson's correlation $0.66 \quad(p=0.007, N=14)$ ] (Fig. 2). Altogether, the data indicate the robustness of this finding and underline the importance of RPL1OP9 in the pathophysiology of psychopathy. In the astrocytes, also mitochondria encoded 16S RNA $(M T-R N R) 2$ showed a four- to sixfold upregulation of RNA expression in the violent offenders (Fig. 2).

Interestingly, opioid receptor delta $1(O P R D 1)$ gene was upregulated in nonviolent offenders as compared with normal controls, but the expression for OPRDI was even lower in the violent offenders as compared with the two other groups, although these results reached only borderline statistical significance (Fig. 1c, Suppl. Table 2). As the OPRD1 gene codes for an opioid receptor delta protein, a protein involved in mediating the effects of opioids often used for substance abuse purposes, and as many violent antisocial offenders often suffer from substance abuse disorders, it was striking that the expression level of this protein was low in the violent offenders. Thus, we did further qPCR analysis for $O P R D 1$ in order to see whether differences between the groups arise in this more accurate analysis. The qPCR analysis pointed toward the same trend of lower expression of OPRD1 in the violent offender group, although this result again reached only borderline statistical significance. Taking all together, ZNF132, RPL1OP9, CDH5, and OPRD1 genes explained $30-92 \%$ of variance of the psychopathy symptomatology, as measured by the PCL-score. Moreover, in fibroblasts, no differences between the studied groups were detected (Suppl. Fig. 4). These findings point out that ZNF132 is mainly overexpressed in neurons and most likely affect the transcriptional regulation of other genes. Results from pathway analyses from neurons are displayed in Supplementary Table 4, and show enrichment in several immune responserelated pathways. No statistically significant enrichments were observed in astrocytes.

Data from proteomic analysis are shown in Fig. 3. Here the largest effect sizes were observed for opioid-binding protein/cell-adhesion molecule (OPCML) in the proteomic analysis and for PSMD3, PEG10, and PCDH19 in phosphoproteome analysis. Of the proteins with significantly higher levels in the proteome analysis, OPCML was the most elevated protein in the violent offenders as compared with controls (6.6-fold change, $p=9.5 \times 10^{-3}$ ). However, also nonviolent substance abusers showed higher OPCML values than controls, indicating that this finding may not be necessarily specific for psychopathy but could be associated with substance dependence.

In the phosphoproteome analysis, in the violent criminals, paternally expressed 10 (PEG10) levels were 51-fold, protocadherin 19 (PCDH19) 37-fold, spectrin beta, nonerythrocytic 5 (SPTBN5) 17-fold, and acyl-CoA synthetase long chain family member 4 (ACSL4) 7-fold higher than controls. Concerning phosphoproteins with lower levels in the violent offenders, levels of a proteasome $26 \mathrm{~S}$ subunit non-ATPase 3 (PSMD3) were 203-fold, and Myosin 1E (MYO1e) 19-fold lower than in controls. 
ڤี

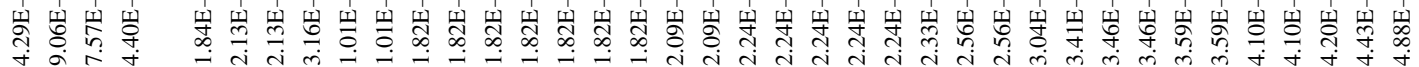

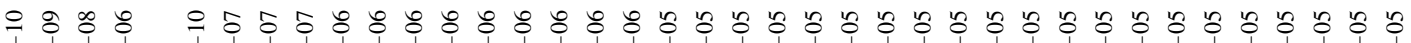

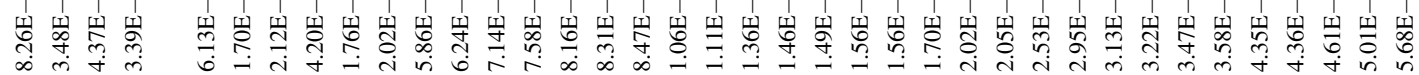

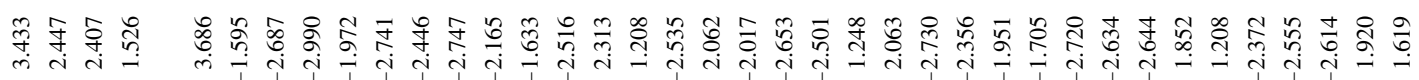

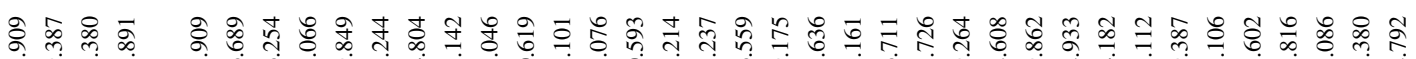

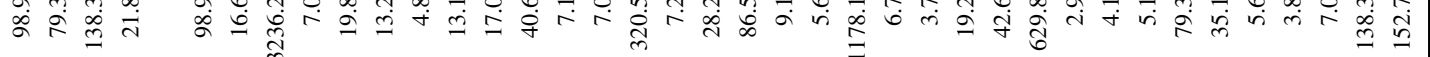
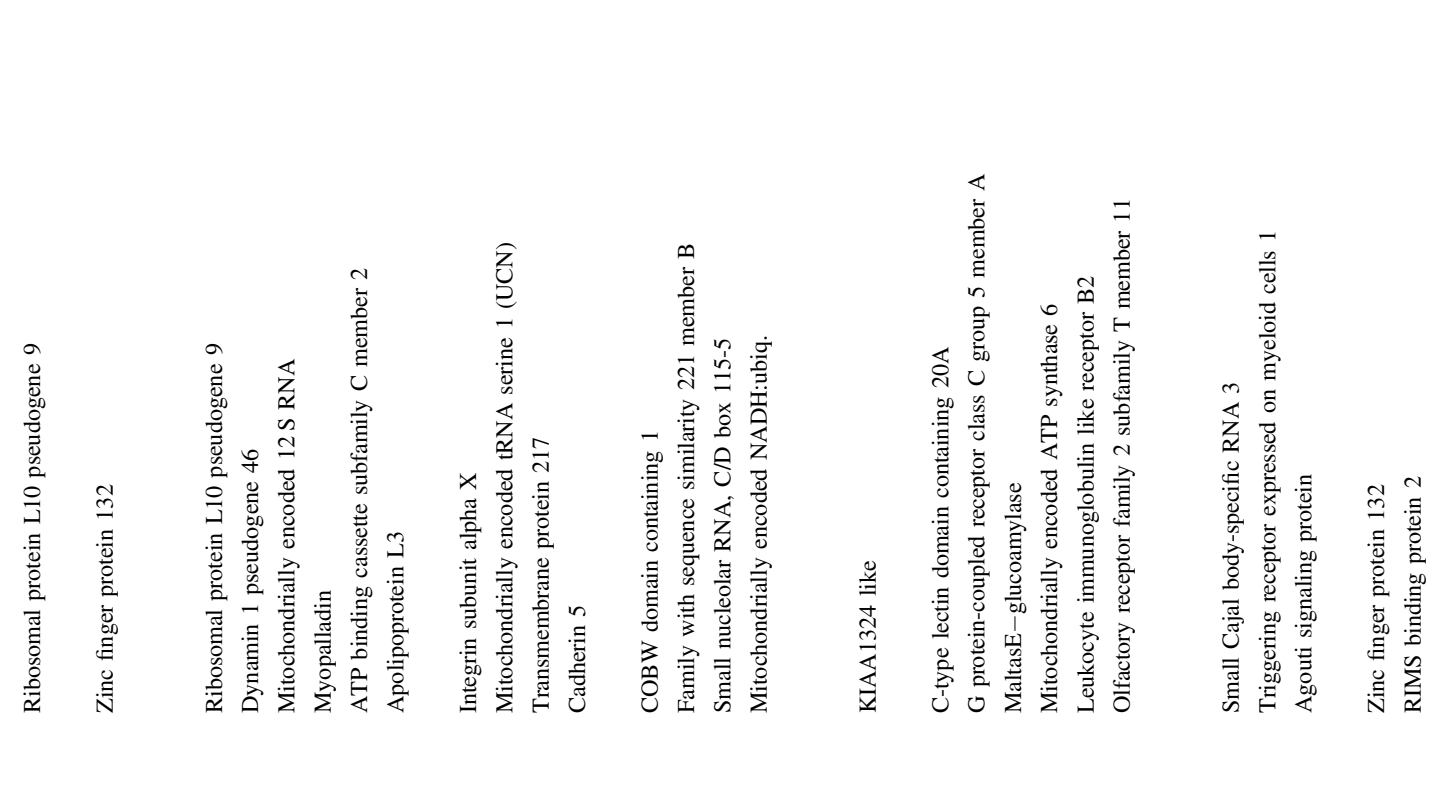

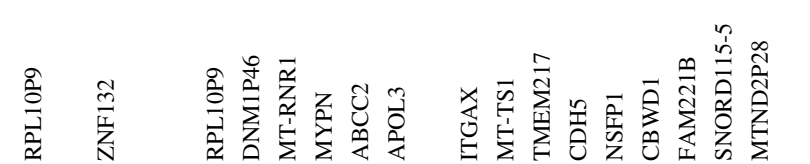
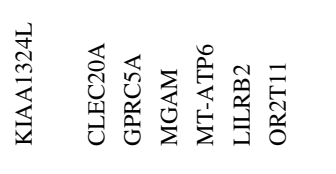

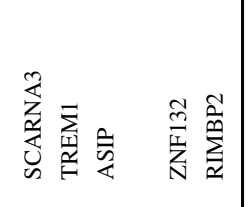

总

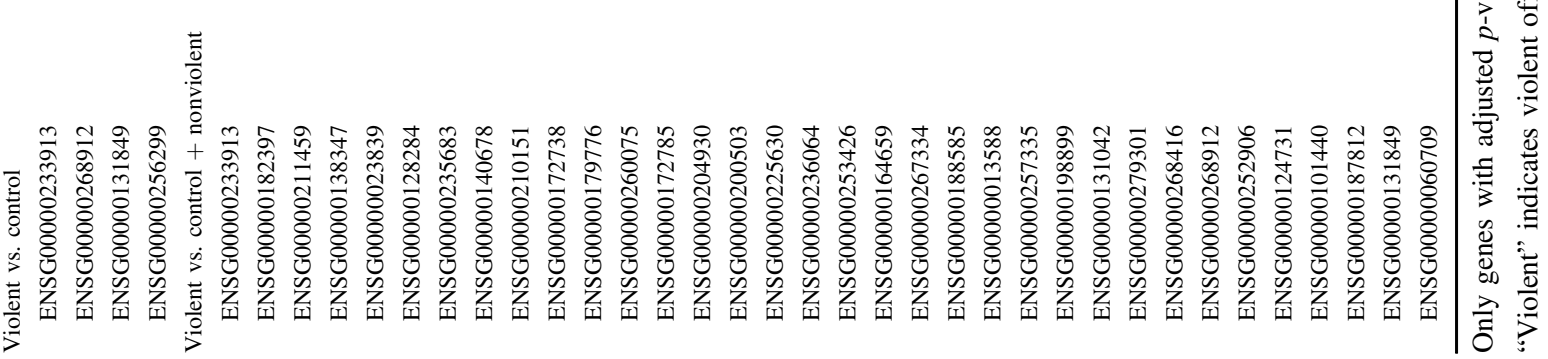



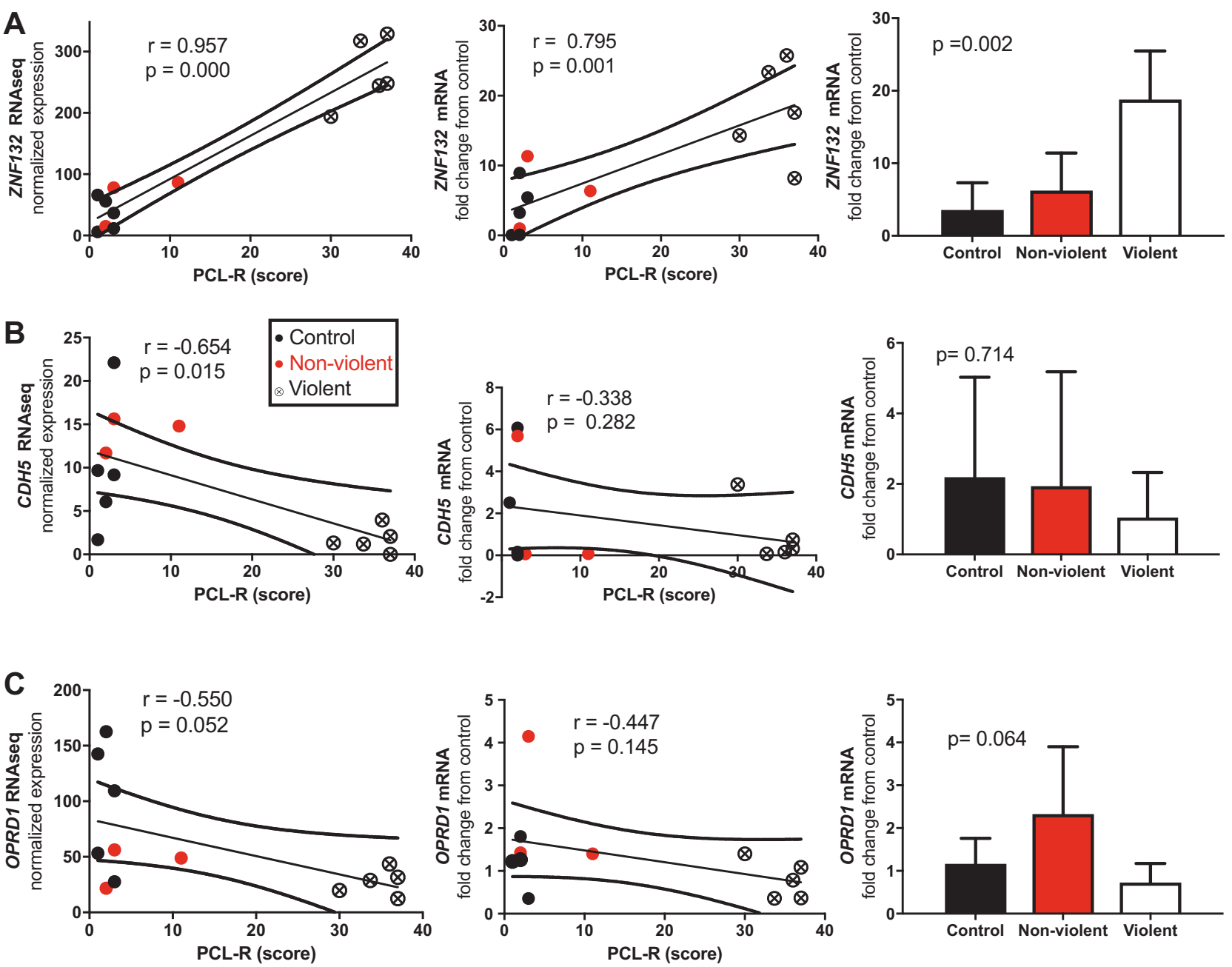

Fig. 1 RNA expression analyses of hiPSCs-derived cortical neurons for a ZNF132, b $C D H 5$, and $\mathbf{c} O P R D 1$ genes. The first graph represents correlation with normalized expression levels and the second with gene expression levels validated by quantitative RT-PCR (qRT-
PCR). The column graph presents mRNA expression levels of gene of interest measured by qRT-PCR. $r$ indicates Pearson correlation coefficient. "Violent" indicates violent offenders, and "nonviolent" indicates individuals with substance abuse but without criminal behavior

\section{Discussion}

To our knowledge, this is the first study to reveal significant alterations in gene expression related to psychopathy. Our results showed that expression levels of RPL109, ZNF132, $C D H 5$, and $O P R D 1$ genes in neurons explained $30-92 \%$ of the severity of psychopathy, and RPL109 expression was significantly associated with degree of psychopathy also in astrocytes. It is remarkable that all the aforementioned genes except $O P R D I$ have been previously linked to autism [17-22], and might thus contribute to the emotional callousness and lack of empathy observed in psychopathic violent offenders. The strongest association was observed for ZNF132, a member of zinc finger Kröppel family associated with several developmental and malignant disorders [23]. It has been also reported that autism gene CHD8 modifies the expression of ZNF132 [18]. The exact function of ZNF132 is unknown but it may be involved in transcriptional regulation. Interestingly, the highest expression levels of ZNF132 mRNA were seen in cortical neurons of violent subjects, while in hiPSCs, no difference between violent and nonviolent subjects was observed. ZNF132 is expressed highly in the cerebellum [24], and a recent study has found that cerebellum can regulate social behavior by controlling dopamine release [25], suggesting that this may contribute to mental disorders, such as autism and schizophrenia. Our results imply that cerebellum may also have a role in severe antisocial behavior.

We observed enrichment in several immune responserelated pathways. This is an interesting finding since a recent study on adult antisocial behavior found enrichment in 7 gene sets, most of which being immune related [9]. This suggests that altered immune response contributes to the pathophysiology of antisocial behavior. 
A

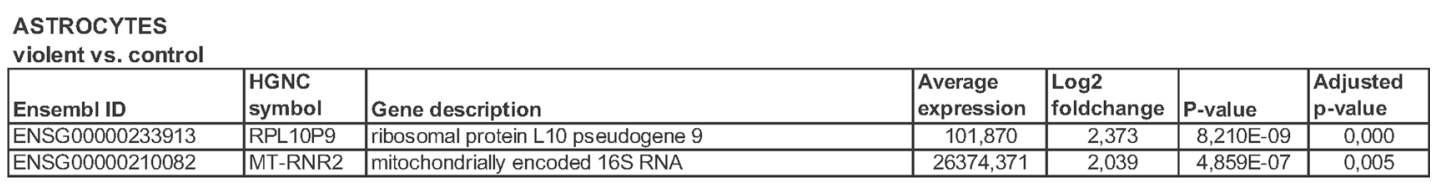

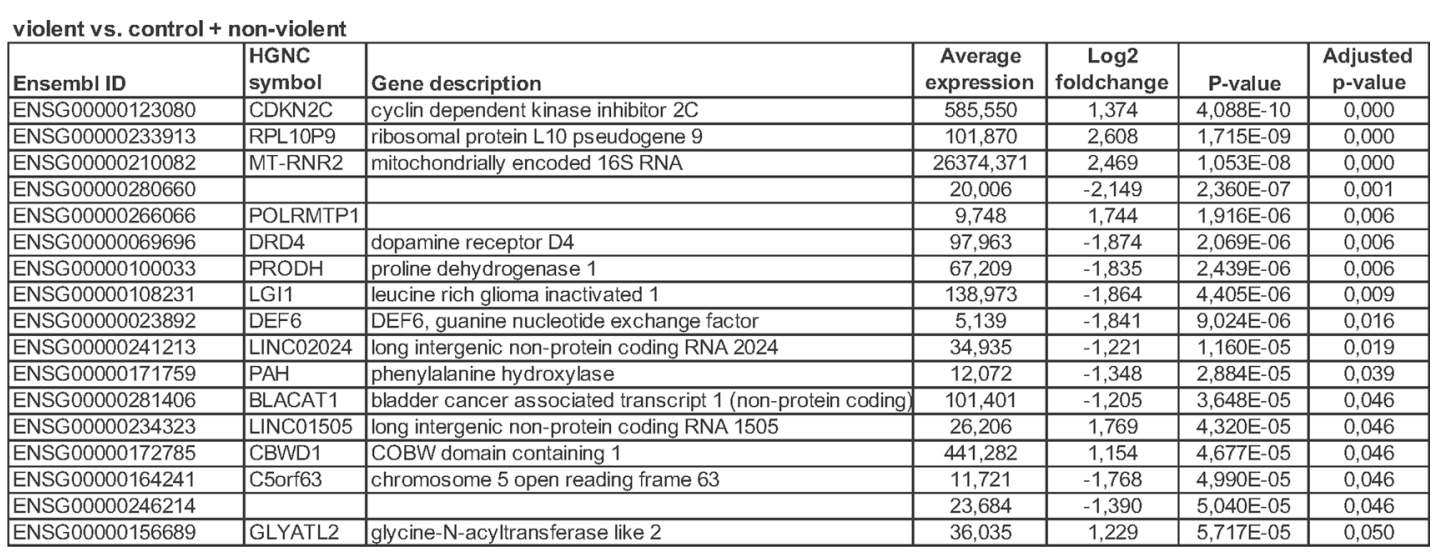

B

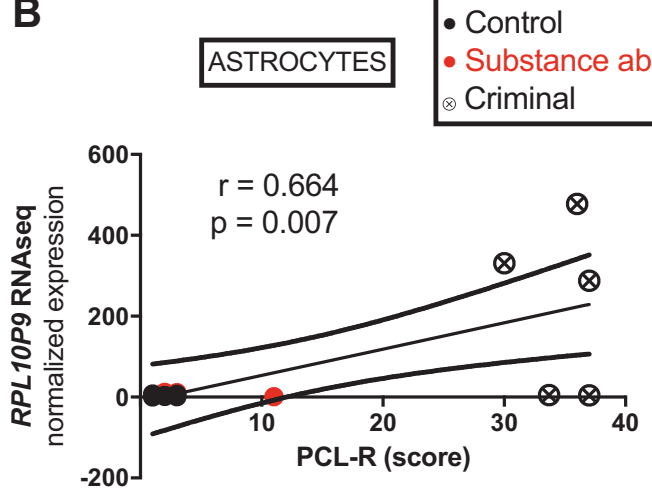

C

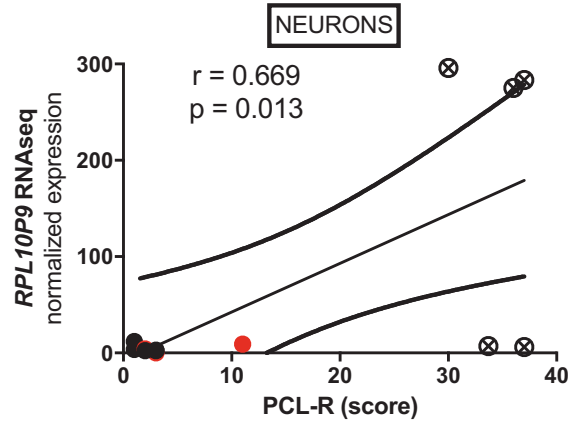

Fig. 2 Transcriptome analyses of differentially expressed genes in hiPSCs-derived astrocytes. a The genes with adjusted $p$-value $<0.05$ and at least twofold up- or downregulation are presented in the table. The correlation of PCL-R score with normalized expression levels for

In proteomic analysis, the most robust finding was upregulation of OPCML. It has been shown to have an accessory role in opioid receptor function, and the gene encoding the protein is highly conserved in mammals. In rats, the accessory role to activate opioid receptors has been shown to be specific for the mu receptor ligands. Differences in $O P C M L$ gene expression have also been detected in patients with schizophrenia, although protein level measurements from post mortem brains have not differed between patients and healthy controls [26].

In phosphoprotein analysis, several proteins were upregulated. Of these, PEG10 is a paternally imprinted gene that uses a rare mechanism for encoding for two different protein products by using the -1 ribosomal frameshift translation, which is well known from retroviruses and retrotransposons, but is extremely rare in humans [27]. In adult mice, the protein is expressed only in the brain and
$R P L 10 P 9$ in $\mathbf{b}$ astrocytes and c neurons. $r$ indicates the Pearson correlation coefficient. "Violent" indicates violent offenders, and "nonviolent" indicates individuals with substance abuse but without criminal behavior

testes, and blocks TGF-B signaling. A paternally imprinted gene such as this one could explain why psychopathy is inherited from father to son. In this study, three of six offenders had a biological father convicted into prison, while none of the mothers had been imprisoned. PCDH19 is a protocadherin, which has been linked to epilepsy [28], autism [29] and behavioral problems, aggression, and photosensitivity. PCDH19 is thought to be a calciumdependent cell-adhesion protein that is primarily expressed in the brain, and has been shown to cause a decrease in the amount of neurosteroids, including adrenocorticotropic hormone, in females. ACSL4 has been associated with $\mathrm{X}$-chromosome linked mental retardation [30] as well as insulin secretion [31]. On the other hand, PSMD3 and MYO1e were substantially downregulated compared with controls. Of these, PSMD3 is an enzyme, an aberration of which contributes to pathogenesis of neurodevelopmental 
A

NEURONS

\begin{tabular}{|c|c|c|c|c|}
\hline \multicolumn{2}{|c|}{ violent vs. control } & \multicolumn{3}{|l|}{ Proteome } \\
\hline EntrezIDs & Symbol & Description & $\begin{array}{l}\text { Log2 fold } \\
\text { change }\end{array}$ & P-value \\
\hline 4978 & OPCML & opioid binding protein/cell adhesion molecule like & 2,729 & $9,50 \mathrm{E}-03$ \\
\hline 7512 & XPNPEP2 & X-prolyl aminopeptidase 2 & 1,960 & $3,91 \mathrm{E}-03$ \\
\hline 3034 & HAL & histidine ammonia-lyase & 1,120 & $5,49 \mathrm{E}-03$ \\
\hline 10457 & GPNMB & glycoprotein nmb & $-2,040$ & 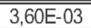 \\
\hline 26063 & DECR2 & 2,4-dienoyl-CoA reductase 2 & $-1,770$ & $4,95 \mathrm{E}-04$ \\
\hline 126961 & $\begin{array}{l}\text { HIST2H3C//HIST } \\
2 \mathrm{H} 3 \mathrm{~A} / \mathrm{HIST} 2 \mathrm{H} 3 \\
\text { D }\end{array}$ & $\begin{array}{l}\text { histone cluster } 2 \mathrm{H} 3 \text { family member c//histone cluster } \\
2 \mathrm{H} 3 \text { family member al/his tone cluster } 2 \mathrm{H} 3 \text { family } \\
\text { member } \mathrm{d}\end{array}$ & $-1,453$ & $3,75 \mathrm{E}-03$ \\
\hline 79892 & MCMBP & minichromosome maintenance complex binding protein & $-1,249$ & $6,44 \mathrm{E}-03$ \\
\hline
\end{tabular}

B
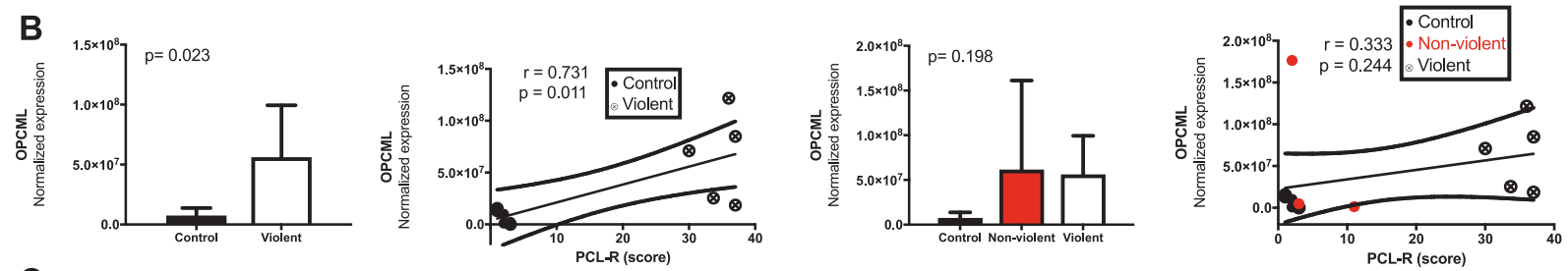

C

NEURONS
violent vs. control
\begin{tabular}{|l|l|l|c|c|}
\hline EntrezIDs & Symbol & Description & $\begin{array}{l}\text { Log2 fold } \\
\text { change }\end{array}$ & P-value \\
\hline 23089 & PEG 10 & paternally expressed 10 & 5,676 & $3,61 \mathrm{E}-05$ \\
\hline 57526 & PCDH19 & protocadherin 19 & 5,197 & $3,69 \mathrm{E}-06$ \\
\hline 51332 & SPTBN5 & spectrin beta, non-erythrocytic 5 & 4,083 & $4,34 \mathrm{E}-05$ \\
\hline 2182 & ACSL4 & acyl-CoA synthetase long chain family member 4 & 2,895 & $1,59 \mathrm{E}-04$ \\
\hline 57697 & FANCM & Fanconi anemia complementation group M & 2,634 & $1,37 \mathrm{E}-04$ \\
\hline 79693 & YRDC & yrdC N6-threonylcarbamoyltransferase domain contain & 2,781 & $2,67 \mathrm{E}-04$ \\
\hline 5564 & PRKAB1 & protein kinase AMP-activated non-catalytic subunit b1 & 2,135 & $2,86 \mathrm{E}-04$ \\
\hline 5709 & PSMD3 & proteasome 26S subunit, non-ATPase 3 & $-7,665$ & $6,71 \mathrm{E}-07$ \\
\hline 10914 & PAPOLA & poly(A) polymerase alpha & $-4,729$ & $4,28 \mathrm{E}-05$ \\
\hline 60485 & SAV1 & salvador family WW domain containing protein 1 & $-4,743$ & $6,32 \mathrm{E}-05$ \\
\hline 84502 & JPH4 & junctophilin 4 & $-5,568$ & $2,10 \mathrm{E}-04$ \\
\hline 4643 & MYO1E & myosin IE & $-4,270$ & $7,03 \mathrm{E}-05$ \\
\hline 201161 & CENPV & centromere protein V & $-3,364$ & $4,41 \mathrm{E}-05$ \\
\hline 7629 & ZNF76 & zinc finger protein 76 & $-3,632$ & $2,16 \mathrm{E}-04$ \\
\hline
\end{tabular}
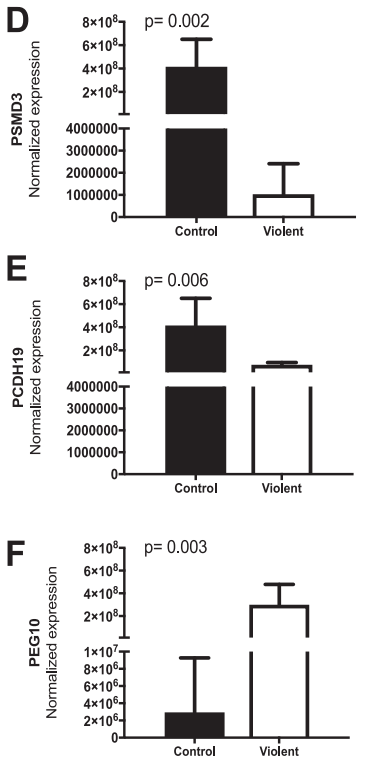
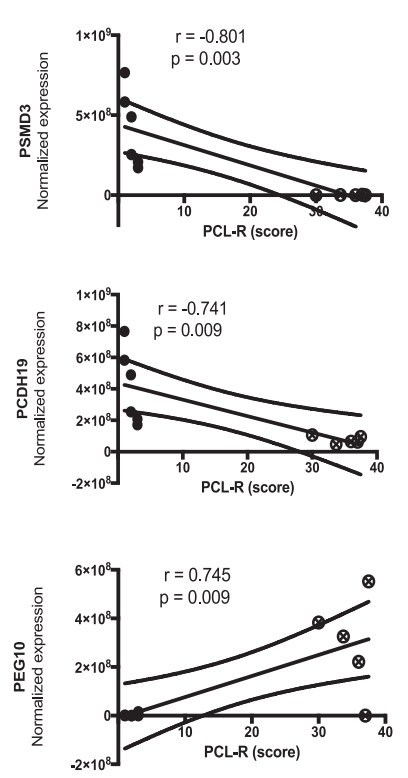

Fig. 3 Proteomic analyses of differentially expressed proteins and phosphoproteins in hiPSCs-derived cortical neurons. a Proteins with adjusted $p$-value $<0.05$ and at least twofold up- or downregulation are presented in the table. $\mathbf{b}$ The normalized expression of opioid-binding protein/cell-adhesion molecule (OPCML) and its correlation with PCL-R score. c Top ten list of phosphoproteins and normalized
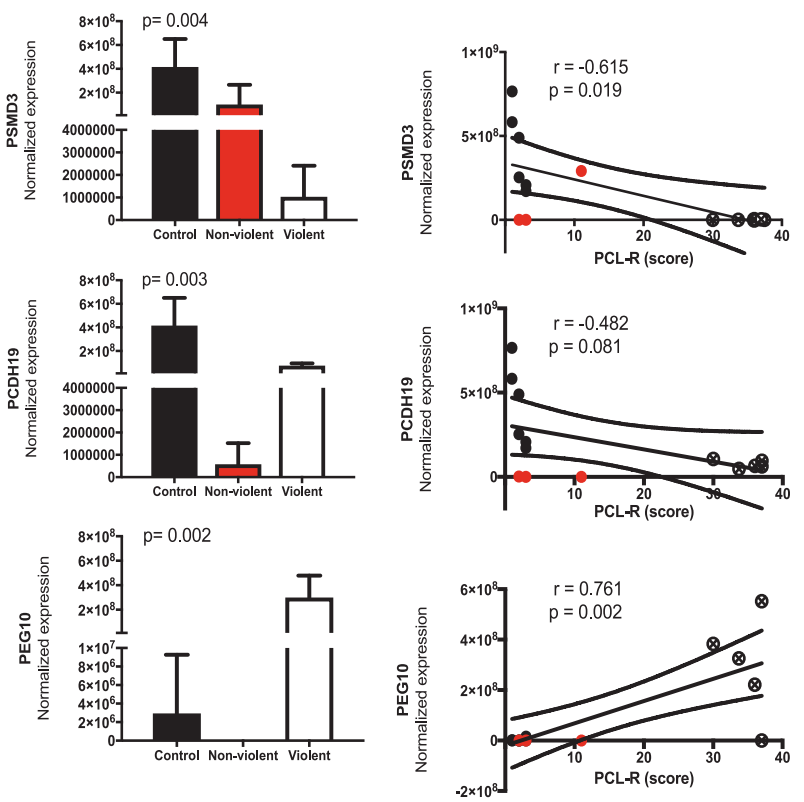

expression and its correlation with PCL-R score for $\mathbf{d}$ 26S proteasome non-ATPase regulatory subunit 3 (PSMD3), e Protocadherin 19 (PCDH19), f Retrotransposon-derived protein (PEG10). $p$-values shown in $\mathbf{a}$ and $\mathbf{c}$ are nominal values, and remained statistically significant $(p<0.05)$ after correction for multiple comparisons in c. $r$ indicates the Pearson correlation coefficient 
and neurodegenerative disorders [32, 33] and insulin resistance [34]. This finding suggests that downregulation of PSMD3 contributes to abnormal glucose metabolism which results into impulsive violent behavior among severely antisocial individuals as has been reported in several studies $[14,35]$. MYO1e has been associated with autism in a single study [36].

In conclusion, expression of ZNF132 in neurons and $R P L 10 P 9$ in both neurons and astrocytes is markedly abnormal among habitually violent offenders and these findings are strongly associated with the degree of psychopathic symptoms. The changes in protein levels observed here point to alteration in insulin sensitivity and glucose metabolism, and previous literature has shown that abnormal glucose metabolism is the only predictor for violent crimes which can surpass the accuracy of PCL-R [35]. We also observed changes in the opioid system, which has been shown to support prosocial functions, such as empathy, among humans and nonhuman primates $[12,13,37,38]$. Our results showing a decrease in the expression of opioid delta receptor gene are in line with these previous findings. A recent theory suggests that a deficient endogenous opioid system contributes to antisocial personality, proposing that antisocial individuals attempt to stimulate their dysfunctional opioid system by the rewarding effect of substance abuse, and impulsive, sensationseeking, aggressive, and promiscuous behavior [11]. Our data suggest that dysfunction of the opioid system contributes to the phenotype of psychopathy, supporting the recently presented idea that partial opioid receptor agonists, such as $(+)$-naloxone might be the first effective treatment for psychopathy [11].

\section{Data availability}

All data needed to evaluate the conclusions in the manuscript are provided in the manuscript or the supplementary material.

Acknowledgements We thank Laila Kaskela, Eila Korhonen and Sara Wojciechowski for technical help in generation and characterization of the stem cell lines, and Ms Aija Räsänen for secretarial assistance.

Funding The study was partially funded by the Ministry of Social Affairs and Health, Finland, through the developmental fund for Niuvanniemi Hospital, Business Finland, Sigrid Juselius Foundation, the University of Helsinki and the University of Eastern Finland.

Author contributions JT and JK conceived the study. ŠL planned and supervised iPSC lines characterizations, differentiation the neurons and sample preparation for RNA and protein sequencing. IO and OV performed skin biopsies and rating of symptoms, KAP derived iPSC lines with YG and characterized them. IH grew and differentiated neurons and PLJV characterized them. MK differentiated the neurons, and prepared RNA and protein samples for sequencing, run qRT-PCR.
JT wrote the first draft of the manuscript with help of JK, ŠL prepared the figures and tables, and all authors contributed to the final version.

\section{Compliance with ethical standards}

Conflict of interest The authors declare that they have no conflict of interest.

Publisher's note: Springer Nature remains neutral with regard to jurisdictional claims in published maps and institutional affiliations.

Open Access This article is licensed under a Creative Commons Attribution 4.0 International License, which permits use, sharing, adaptation, distribution and reproduction in any medium or format, as long as you give appropriate credit to the original author(s) and the source, provide a link to the Creative Commons license, and indicate if changes were made. The images or other third party material in this article are included in the article's Creative Commons license, unless indicated otherwise in a credit line to the material. If material is not included in the article's Creative Commons license and your intended use is not permitted by statutory regulation or exceeds the permitted use, you will need to obtain permission directly from the copyright holder. To view a copy of this license, visit http://creativecommons. org/licenses/by/4.0/.

\section{References}

1. Hare RD. The Hare Psychopathy Checklist - Revised (PCL-R). 2nd ed. Toronto, ON, Canada: Multi-Health Systems; 2003.

2. Fazel S, Danesh J. Serious mental disorder in 23000 prisoners: a systematic review of 62 surveys. Lancet. 2002;359:545-50.

3. Gibbon S, Duggan C, Stoffers J, Huband N, Völlm BA, Ferriter $\mathrm{M}$, et al. Psychological interventions for antisocial personality disorder. Cochrane Database Syst Rev. 2010;16:CD007668.

4. Vitale JE, Smith SS, Brinkley CA, Newman JP. The reliability and validity of the Psychopathy Checklist - Revised in a sample of female offenders. Crim Justice Behav. 2002;29:202-31.

5. Tiihonen J, Rautiainen MR, Ollila HM, Repo-Tiihonen E, Virkkunen M, Palotie A, et al. Genetic background of extreme violent behavior. Mol Psychiatry. 2015;20:786-92.

6. Ferguson CJ. Genetic contributions to antisocial personality and behavior: a meta-analytic review from an evolutionary perspective. J Soc Psychol. 2010;150:160-80.

7. Rautiainen MR, Paunio T, Repo-Tiihonen E, Virkkunen M, Ollila HM, Sulkava S, et al. Genome-wide association study of antisocial personality disorder. Transl Psychiatry. 2016;6:e883.

8. Tielbeek JJ, Johansson A, Polderman TJC, Rautiainen MR, Jansen P, Taylor M, et al. Genome-wide association studies of a broad spectrum of antisocial behavior. JAMA Psychiatry. 2017;74:1242-50.

9. Salvatore JE, Edwards AC, McClintick JN, Bigdeli TB, Adkins A, Aliev F, et al. Genome-wide association data suggest ABCB1 and immune-related gene sets may be involved in adult antisocial behavior. Transl Psychiatry. 2015;5:e558.

10. McIntosh LA, Marion MC, Sudman M, Comeau ME, Becker ML, Bohnsack JF, et al. Genome-wide association meta-analysis reveals novel juvenile idiopathic arthritis susceptibility loci. Arthritis Rheuma. 2017;69:2222-32.

11. Bandelow B, Wedekind D. Possible role of a dysregulation of the endogenous opioid system in antisocial personality disorder. Hum Psychopharmacol. 2015;30:393-415.

12. Nummenmaa L, Tuominen L. Opioid system and human emotions. Br J Pharm. 2018;175:2737-49. 
13. Nummenmaa L, Tuominen L, Dunbar R, Hirvonen J, Manninen S, Arponen E, et al. Social touch modulates endogenous $\mu$-opioid system activity in humans. Neuroimage. 2016;138:242-7.

14. Virkkunen M, Rissanen A, Franssila-Kallunki A, Tiihonen J. Low non-oxidative glucose metabolism and violent offending: an 8-year prospective follow-up study. Psychiatry Res. 2009; 168:26-31.

15. Hicks AU, Lappalainen RS, Narkilahti S, Suuronen R, Corbett D, Sivenius J, et al. Transplantation of human embryonic stem cellderived neural precursor cells and enriched environment after cortical stroke in rats: cell survival and functional recovery. Eur $\mathbf{J}$ Neurosci. 2009;29:562-74.

16. Oksanen M, Petersen AJ, Naumenko N, Puttonen K, Lehtonen Š, Gubert Olivé M, et al. PSEN1 mutant iPSC-derived model reveals severe astrocyte pathology in Alzheimer's disease. Stem Cell Rep. 2017;9:1885-97.

17. O'Roak BJ, Vives L, Girirajan S, Karakoc E, Krumm N, Coe BP, et al. Sporadic autism exomes reveal a highly interconnected protein network of de novo mutations. Nature. 2012;485:246-50.

18. Wang P, Mokhtari R, Pedrosa E, Kirschenbaum M, Bayrak C, Zheng D, et al. CRISPR/Cas9-mediated heterozygous knockout of the autism gene CHD8 and characterization of its transcriptional networks in cerebral organoids derived from iPS cells. Mol Autism. 2017;8:11.

19. Klauck SM, Felder B, Kolb-Kokocinski A, Schuster C, Chiocchetti A, Schupp I, et al. Mutations in the ribosomal protein gene RPL10 suggest a novel modulating disease mechanism for autism. Mol Psychiatry. 2006;11:1073-84.

20. Chiocchetti A, Pakalapati G, Duketis E, Wiemann S, Poustka A, Poustka F, et al. Mutation and expression analyses of the ribosomal protein gene RPL10 in an extended German sample of patients with autism spectrum disorder. Am J Med Genet A. 2011;155A:1472-5.

21. Chiocchetti AG, Haslinger D, Boesch M, Karl T, Wiemann S, Freitag CM, et al. Protein signatures of oxidative stress response in a patient specific cell line model for autism. Mol Autism. 2014;5:10.

22. Redies C, Hertel N, Hübner CA. Cadherins and neuropsychiatric disorders. Brain Res. 2012;1470:130-44.

23. Tommerup N, Vissing H. Isolation and fine mapping of 16 novel human zinc finger-encoding cDNAs identify putative candidate genes for developmental and malignant disorders. Genomics. 1995;27:259-64.

24. Gtex portal. https://gtexportal.org/home/gene/ZNF132.

25. Carta I, Chen CH, Schott AL, Dorizan S, Khodakhah K. Cerebellar modulation of the reward circuitry and social behavior. Science. 2019;363:eaav0581.

26. Umeda-Yano S, Hashimoto R, Yamamori H, Weickert CS, Yasuda Y, Ohi K, et al. Expression analysis of the genes identified in GWAS of the postmortem brain tissues from patients with schizophrenia. Neurosci Lett. 2014;568:12-16.

27. Lux H, Flammann H, Hafner M, Lux A. Genetic and molecular analyses of PEG10 reveal new aspects of genomic organization, transcription and translation. PLoS ONE. 2010;5:e8686.

28. Kolc KL, Sadleir LG, Scheffer IE, Ivancevic A, Roberts R, Pham D, et al. A systematic review and meta-analysis of 271 PCDH19variant individuals identifies psychiatric comorbidities, and association of seizure onset and disease severity. Mol Psychiatry. 2019;24:241-51.

29. Breuillard D, Leunen D, Chemaly N, Auclair L, Pinard JM, Kaminska A, et al. Autism spectrum disorder phenotype and intellectual disability in females with epilepsy and PCDH-19 mutations. Epilepsy Behav. 2016;60:75-80.

30. Meloni I, Muscettola M, Raynaud M, Longo I, Bruttini M, Moizard MP, et al. FACL4, encoding fatty acid-CoA ligase 4 , is mutated in nonspecific X-linked mental retardation. Nat Genet. 2002;30:436-40.

31. Ansari IH, Longacre MJ, Stoker SW, Kendrick MA, O'Neill LM, Zitur LJ, et al. Characterization of Acyl-CoA synthetase isoforms in pancreatic beta cells: Gene silencing shows participation of ACSL3 and ACSL4 in insulin secretion. Arch Biochem Biophys. 2017;618:32-43.

32. Kim JH, Shinde DN, Reijnders MRF, Hauser NS, Belmonte RL, Wilson GR, et al. De novo mutations in SON disrupt RNA splicing of genes essential for brain development and metabolism, causing an intellectual-disability syndrome. Am J Hum Genet. 2016;99:711-9.

33. Kim JE, Hong YH, Kim JY, Jeon GS, Jung JH, Yoon BN, et al. Altered nucleocytoplasmic proteome and transcriptome distributions in an in vitro model of amyotrophic lateral sclerosis. PLoS ONE. 2017;12:e0176462.

34. Zheng JS, Arnett DK, Parnell LD, Lee YC, Ma Y, Smith CE, et al. Genetic variants at PSMD3 interact with dietary fat and carbohydrate to modulate insulin resistance. J Nutr. 2013;143:354-61.

35. Virkkunen M, Rawlings R, Tokola R, Poland RE, Guidotti A, Nemeroff $\mathrm{C}$, et al. CSF biochemistries, glucose metabolism, and diurnal activity rhythms in alcoholic, violent offenders, fire setters, and healthy volunteers. Arch Gen Psychiatry. 1994;51:20-27.

36. $\mathrm{Hu} \mathrm{H}$, Coon $\mathrm{H}$, Li M, Yandell M, Huff CD. VARPRISM: incorporating variant prioritization in tests of de novo mutation association. Genome Med. 2016;8:91.

37. Nummenmaa L, Manninen S, Tuominen L, Hirvonen J, Kalliokoski KK, Nuutila P, et al. Adult attachment style is associated with cerebral $\mu$-opioid receptor availability in humans. Hum Brain Mapp. 2015;36:3621-8.

38. Rütgen M, Seidel EM, Silani G, Riečanský I, Hummer A, Windischberger $\mathrm{C}$, et al. Placebo analgesia and its opioidergic regulation suggest that empathy for pain is grounded in self pain. Proc Natl Acad Sci USA. 2015;112:E5638-E5646. 